\title{
DIREITO TRIBUTÁRIO: AÇÃO DE REPETIÇÃO DE INDÉBITOS TRIBUTÁRIOS
}

Andreas Gabriel Ferreira Miranda

Universidade do Oeste Paulista - UNOESTE, Curso de Direito, Presidente Prudente, SP. E_mail: andreasferreira50@gmail.com

\section{RESUMO}

A repetição de indébitos surge na ordem tributária na seção do Código Tributário Nacional que trata sobre os pagamentos indevidos, sendo assim entende-se a repetição como pagamento duplo do tributo, sendo assim, a ordem jurídica concede ao tributado o direito de reaver o que foi pago a mais, defendido na esfera cível, a repetição de indébitos e tema bastante discutido na orbita do Direito Tributário, sendo cercado de normas e dificuldades para seu entendimento.

Palavras-chave: TRIBUTO. REPETIÇÃO. PAGAMENTO INDEVIDO. ERRO. RESTITUIÇÃO

\section{TAX LAW: ACTION OF REPETITION OF TAX INDEMBERS}

\begin{abstract}
The repetition of indébito arises in the tax order in the section of the National Tax Code that deals with the undue payments, and this is understood as the repetition as double payment of the tax, and thus, the legal order grants the taxed the right to recover what was defended in the civil sphere, the repetition of indébito and subject much discussed in the orbit of the Tax Law, being surrounded of norms and difficulties for its understanding.

Keywords: TRIBUTE. REPETITION. PAYMENT WITHOUT. ERROR. RESTITUTION
\end{abstract}




\section{INTRODUÇÃO}

O indébito tributário é compreendido na esfera processual e material do Direito tributário nacional, encontra-se também defeso na legislação cível do país. Na esfera processual o indébito repetido do direito a abertura de Ação de Repetição de indébito, que tem por escopo evitar o enriquecimento ilícito do órgão tributador. "A doutrina tem debatido a questão de saber se o 'valor' a ser restituído constituiria 'tributo' ou exação de natureza 'privada', na medida em que, se houve um recolhimento 'a maior' ou 'errôneo', não seria, propriamente, 'tributo'.". (CASSONE; ROSSI; CASSONE, 2017, p. 216)

A sistemática processual abre para o ramo do direito material tributário a missão de demonstrar uma série de elementos que dão ao tributado o direito ao ressarcimento ou não do quantum repetido ou majorado.

Pela conciliação do direito material e processual tributário surge várias possibilidades que inclusive se defendem em outros âmbitos jurídicos como no cível e penal.

Após breve reflexão, o presente artigo tem como objetivo geral a exposição dos principais elementos da repetição de indébito tributário, elencando as polêmicas supervenientes do direito material e processual, além de demonstrar a forma como as cortes julgadoras tem entendido e julgado casos envolvendo o tema.

\section{MÉTODO}

O presente estudo seguirá o método exploratório, dedutivo e dialético com emprego de pesquisa à legislação, doutrina e jurisprudência acerca da repetição de indébitos, abordando a sistemática processual e material na qual ela se sustenta.

\section{A REPETIÇÃO DE INDÉBITOS NO CTN}

Levando em consideração a matéria legislada pelo código tributário nacional, bem como, a relevância da matéria nas cortes superiores do país, a repetição de indébito tem base legal fundada ao artigo 165 do Código Tributário Nacional que assim a dispõe:

O sujeito passivo tem direito, independentemente de prévio protesto, à restituição total ou parcial do tributo, seja qual for a modalidade do seu pagamento, ressalvado o disposto no $\S 40$ do artigo 162, nos seguintes casos:

I - Cobrança ou pagamento espontâneo de tributo indevido ou maior que o devido em face da legislação tributária aplicável, ou da natureza ou circunstâncias materiais do fato gerador efetivamente ocorrido;

II - Erro na edificação do sujeito passivo, na determinação da alíquota aplicável, no cálculo do montante do débito ou na elaboração ou conferência de qualquer documento relativo ao pagamento;

III - reforma, anulação, revogação ou rescisão de decisão condenatória. (BRASIL, 2018).

O texto legal trata de maneira abrangente todas as espécies de restituição de tributos pagos indevidamente independe da razão que leva ao pagamento indevido, possibilitando o erro de ambos os sujeitos das relações tributarias, sem exclusão da possibilidade de erro, revogação, rescisão ou anulação e reforma.

Nos casos onde refere-se a tributos indiretos há previsão legal de transferência dos encargos financeiros apenas a quem de direito provar que assumiu o referido encargo "art.166 [...]transferência do respectivo encargo financeiro somente será feita a quem prove haver assumido referido encargo[...]". (BRASIL, 1966). O mesmo entendimento possui o Supremo Tribunal Federal, quando redigiu súmula para pacificar o entendimento das cortes diante da 
transferência dos encargos. Tal fenômeno chama-se repreclusão e fato tratado na sumula 556 do STF.

"sumula 556- Cabe restituição do tributo pago indevidamente, quando reconhecido por decisão que o contribuinte de jure não recuperou do contribuinte de facto o quantum respectivo." (BRASIL. Supremo Tribunal Federal, 1969).

O fenômeno tratado pela sumula supracitada é conhecido no mundo jurídico como repercussão enunciando que:

os valores indevidamente pagos a título de tributos só podem ser judicialmente reconhecidos e restituídos caso o contribuinte de direito não tenha recuperado do contribuinte de fato o citado valor. $O$ contribuinte de direito poderá provar a assunção do ônus tanto pela cabal demonstração de que o encargo foi transferido, bem como pela ocorrência do ressarcimento feito ao contribuinte de fato. (OLIVEIRA, 2011).

Nesse sentido entende que a demonstração de direito é incumbida a quem tem interesse de comprovar o pagamento indevido, dando por essa razão o direito a ingresso com a ação de repetição de indébitos, onde buscar-se-á provar a existência de pagamento indevido buscando o ressarcimento do "quantum" a mais, por exigência do CTN a necessidade de prova do ônus imposto.

\section{LEGITIMIDADE PARA REQUERER A RESTITUIÇÃO DOS VALORES PAGOS}

Quando tratamos de tributos diretos, a parte ativa possui a legitimidade para requerer a restituição do tributo pago, ressalvada previsão legal contraria. Porém, não são todos os tributos que possui essa mesma normatização, no caso de tributos ISS que são regidos por lei complementar a regência prende-se a lei especial visto o caráter da especialidade. Existindo norma que exija o destaque do ISS na Nota Fiscal, como previsto na legislação que regulamenta o IPI e ICMS, a legitimidade será aquela proposta pelo art. 166 CTN, inexistindo norma, não há utilização do art.166, sendo assim o pagador direito legitimo a requerer a devolução. (CASSONE; ROSSI; CASSONE, 2017, p.219).

O artigo 166 do CTN é serio obstáculo para os contribuintes na obtenção de sua restituição de indébito, todavia se não analisado o referido artigo, torna-se impossível descobrir a legitimidade para requisição, pois pode infringir dificuldade na obtenção de autorização do legitimo contribuinte para que requeira a restituição do valor pago indevidamente.

\section{INCIDÊNCIA DE JUROS DE MORA A PENALIDADES PECUNIÁRIAS}

Sendo possível a restituição do indébito de forma total ou parcial, sobre ele haverá a incidência de juros, moras e penalidades pecuniárias, a legislação prevê essa possibilidade no art. 167 do CTN.

Art. 167. A restituição total ou parcial do tributo dá lugar à restituição, na mesma proporção, dos juros de mora e das penalidades pecuniárias, salvo os referentes a infrações de caráter formal não prejudicadas pela causa da restituição.

Parágrafo único. A restituição vence juros não capitalizáveis, a partir do trânsito em julgado da decisão definitiva que a determinar. (BRASIL, 2018).

Diante da previsão de cabimento legal e incidência de juros e moras e penalidades pecuniárias, ingressando com ação judicial, diante da morosidade do sistema judiciário o valor pago indevido será corrigido, sendo assim, o tempo de espera não traz ônus ao pagador do 
tributo. Porém, como previsto no próprio texto legal esse direito de capitalização termina com o transito em julgado após expedição da sentença.

\section{PRAZO DE PLEITO E PRESCRIÇÃO PARA REQUISIÇÃO DA RESTITUIÇÃO DE INDÉBITOS}

A legislação tributária prevê prazos para que se faça a requisição de restituição de indébitos, como também, prevê, prazo prescricional par o mesmo fim.

Elencado no art.168 do CTN com a seguinte redação:

Art. 168. O direito de pleitear a restituição extingue-se com o decurso do prazo de 5 (cinco) anos, contados:

| - Nas hipóteses dos incisos I e || do artigo 165, da data da extinção do crédito tributário;

II - Na hipótese do inciso III do artigo 165, da data em que se tornar definitiva a decisão administrativa ou passar em julgado a decisão judicial que tenha reformado, anulado, revogado ou rescindido a decisão condenatória.

Previsto prazo prescricional de 5 anos, o pagador, poderá exigir a restituição do valor pago indevidamente da data da extinção do credito tributário, ou seja, seu efetivo pagamento ao órgão tributador, ou após decisão judicial que rescinde a condenação.

A prescrição também se encontra em lei especial, onde o legislador tenta mostrar melhor efetividade ao art. 168 do CTN, exemplo é a lei complementar $n^{\circ} 118$ de 2005, que traz a data onde o prazo de pleito se inicia e quando este se extingue.

\section{DA PRESCRIÇÃO}

Prescreve-se a pretensão de restituição dos valores pagos dois anos após decisão administrativa que denegar o valor a ser restituído. O prazo prescricional também se interrompe com a adjudicação de ação judicial.

No caso do art.169 CTN, não trata de ação de repetição de indébitos, mas sim, ação anulatória administrativa. (CASSONE; ROSSI; CASSONE, 2017, p.227) dispõe o seguinte artigo:

Art. 169. Prescreve em dois anos a ação anulatória da decisão administrativa que denegar a restituição.

Parágrafo único. O prazo de prescrição é interrompido pelo início da ação judicial, recomeçando o seu curso, por metade, a partir da data da intimação validamente feita ao representante judicial da Fazenda Pública interessada. (BRASIL, 2018)

Segundo Cassone; Rossi; Cassone, (apud MACHADO, 2009, p. 428/429) ao falar sobre o referido artigo:

Não obstante vacilações iniciais, a jurisprudência firmou-se no sentido de que o pedido de restituição na via administrativa não é uma condição para a propositura da ação de repetição do indébito. E especialmente nos casos em que a Fazenda Pública, ao contestar a ação, entra no mérito opondo-se o pedido, negando, assim, o direito à repetição, aquela preliminar de ausência de interesse processual em razão da não formulação do pedido na via administrativa, passou a jurisprudência a rejeitar aquela arguição, julgando, no mérito, a pretensão do contribuinte.

Assim, é desnecessário o pedido na via administrativa, e considerando também que a Administração Tributária em regra indefere os pedidos de restituição, pensamos que o contribuinte não deve formular pedido administrativo, com o que evitará a incidência da norma albergada pelo art. 169 do Código Tributário Nacional. Isso, porém, não nos dispensa de examinar a questão de saber se a citada norma é válida ou não, em face dos princípios constitucionais. 
Sendo assim, a ação judicial de repetição de indébitos não se confunde com as vias administrativa, porém, aquela, serve para esta como marco final do prazo para intentar com a ação de repetição de indébitos, visto que um prazo suspende o outro.

\section{CONCLUSÃO}

Diante do exposto conclui-se que para fins processuais, a ação de repetição de indébitos segue um parâmetro bem delimitado dentro da orbita tributaria nacional, sendo por ela regimentada, e resguardada a independência da esfera judicial diante da administrativa.

A ação serve como defesa diante da inercia administrativa, ou omissão da mesma. Sendo potente para resguardo daquele que indevidamente contribui tributos onerosos, duplos ou indevidos. Sendo de fundamental importância a observância dos direitos das pessoas naturais, diante da orbita administrativa.

O processo tributaria se funde ao direito material, com isso forma aparato potente para satisfação das lides dentro do seu âmbito de proteção. Deve ser observada a precisão com que o texto legal trata a ação destinada a restituição de valores pagos indevidamente, para obtenção de êxito nas práticas advocatícias e sociais.

\section{REFERÊNCIAS}

BRASIL. Código Tributário Nacional. Coordenação Flavia Alves Bravin. 28. ed. São Paulo: Saraiva, 2018.

BRASIL. Supremo Tribunal Federal. Embargos. Embargos conhecidos e providos. Recurso Extraordinário $n^{\circ}$ 58.660. Embargante: CIA. Progresso Nacional - Industria Brasileira de Produto Alimentícios e Conexos. Embargada: Fazenda do Estado de São Paulo. Relator Ministro Amaral santos. Brasília, 10 de abril de 1969. Disponível em:< http://www.stf.jus.br/portal/jurisprudencia/menuSumarioSumulas.asp?sumula=2210>. Acesso em: 07 ago. 2018.

CASSONE, V.; ROSSI, J.; CASSONE, M. T. Processo Tributário: Teoria e Prática, 15.ed. São Paulo: Atlas, 2017 
OLIVEIRA, Michele Cristina Souza Colla De. Elementos da Ação de Repetição de Indébitos Tributários, Jurisway. São Paulo: set. 2011. Disponível em: <https://www.jurisway.org.br/v2/dhall.asp?id_dh=6551>. Acesso em: 07 ago. 2018 